\title{
Correction to: Cloud Computing, Big Data \& Emerging Topics
}

\author{
Enzo Rucci (D), Marcelo Naiouf (D), Franco Chichizola (D), \\ and Laura De Giusti iD
}

\section{Correction to: \\ E. Rucci et al. (Eds.): Cloud Computing, Big Data \& Emerging Topics, CCIS 1291, https://doi.org/10.1007/978-3-030-61218-4}

\begin{abstract}
Some errors were present in the originally published bookfrontmatter. The following modifications were made:

The affiliations for editors Enzo Rucci, Marcelo Naiouf, and Franco Chichizola have been corrected as "III-LIDI, Facultad de Informatica Universidad Nacional de La Plata, La Plata, Argentina".
\end{abstract}

